\title{
Severe periodontal destruction in a patient with advanced anemia: A case report
}

\author{
Hasan Hatipoglu' \\ Mujgan Gungor Hatipoglu² \\ L. Berna Cagirankaya ${ }^{3}$ \\ Feriha Caglayan ${ }^{4}$
}

\section{ABSTRACT}

Anemia is a worldwide health problem that manifests in different types. This illness has some causes, which affect body health generally. Studies have shown that some anemia types make humans more sensitive to infections.

A 23-year-old woman was referred to our clinic with complaints about tooth mobility. Generalized severe alveolar bone loss was verified by a radiographic examination. After a comprehensive clinical examination and taking her medical history, we decided to schedule a medical consultation with a physician. Medical consultation revealed that the patient suffered from severe anemia. Her periodontal treatment was modified because of her systemic situation. After treatment, the patient was monitored for one year. Her periodontal and systemic statuses were stable during this period.

In this case report, severe periodontal destruction was observed in a patient with severe iron and $\mathrm{B}_{12}$ deficiency anemia. (Eur J Dent 2012;6:95-100)

Key words: Anemia, alveolar bone loss, periodontitis, diagnosis

This case report was presented in 85th IADR General Session, Ernest N. Morial Convention Center, New Orleans, Louisiana, USA, 21-24 May 2007.

1 Research and Training Hospital, Dental Clinic/ Periodontology, Dumlupınar University, Kutahya, TURKIYE.

2 Research and Training Hospital, Dental Clinic/ Oral Diagnosis ve Radiology, Dumlupınar University, Kütahya, TURKIYE.

3 Department of Oral Diagnosis and Radiology, Faculty of Dentistry, Hacettepe University, Ankara, TURKIYE.

4 Department of Periodontology, Faculty of Dentistry, Hacettepe University, Ankara, TURKIYE.

- Corresponding author: Dr. Mujgan Gungor Hatipoglu, Research and Training Hospital, Dental Clinic/Oral Diagnosis ve Radiology, Dumlupınar University, Kütahya, TURKIYE.

Tel: +90 2742652031 Fax: +90 2742652056

Email: mujgan121dyahoo.com

\section{INTRODUCTION}

Periodontitis is one of the most common oral and dental health problems currently, and it not only requires clinical attention but also merits further clinical research to be resolved. As periodontal disorders are known to be associated with several systemic disorders-such as diabetes, stroke, neoplasms, etc.-most patients with periodontitis require further medical evaluation and management to treat their oral and health problems and to prevent further dental losses.'

Recently, several reports have been published that indicate a relationship between anemia and 
periodontitis. ${ }^{2-9}$ These clinically interesting reports have mentioned the importance of clinical treatment of anemia in order to obtain an acceptable oral health status. Thus, researchers should investigate the relation between periodontitis and anemia.

Currently, two significant theories are available to explain the relationship between severe anemia and periodontitis. Some researchers have provided evidence for improved periodontal health after correction of some anemia types. ${ }^{10}$ However, other studies have reported improved anemia with the control of periodontal disturbances. ${ }^{6-8} \mathrm{Sev}$ eral mechanisms have been suggested to explain these observations, but there is currently limited high level clinical evidence that applies to all patients with anemia and periodontitis.

This case report presents a patient with severe periodontal destruction, which may be associated with severe anemia of chronic iron and vitamin $B_{12}$ deficiency.

\section{CASE REPORT}

A 23-year-old woman presented with tooth mobility to our dentistry clinic at the Hacettepe University Faculty of Dentistry, Ankara, Turkiye. The patient's personal medical and dental histories were not significant in revealing any systemic disorder. Furthermore, her family history did not reveal any specific clinical condition. She was a non-smoker and was not a regular drug user. In her intra-oral examination, oral mucosa and gingiva were found to be noticeably pale. Significant periodontal bleeding and purulence on probing and increased probing depth (up to $10 \mathrm{~mm}$ ) were the additional significant findings. Otherwise, the patient's oral hygiene was fair, with little or no visible plaque accumulation or calculus. Generalized severe alveolar bone loss was demonstrated via a radiographic examination (Figure 1).

During her dental examination and systemic medical evaluation, the patient complained about easy exhaustion with a few movements and excessive menstrual bleeding during her latest periods. With medical consultation and a through medical evaluation, the patient was diagnosed to have severe anemia of iron and vitamin $B_{12}$ deficiency. Dental interventions were delayed until medical restorations of these specific deficits. Iron replacement was given with ferroglycine sulphate capsules. The vitamin $\mathrm{B}_{12}$ deficit was restored with I.M. injections of $1000 \mu \mathrm{g} /$ day cyanocobalamine for five days, which then were continued to $1000 \mu \mathrm{g} /$ week for four weeks; monthly check-ups for patient maintenance were also conducted. Baseline blood test values are reviewed in Table 1, with the control values after three and six months of the treatment described above.

After the medical consultation, oral hygiene education and scaling and root planning were realized. Then, $0.2 \%$ chlorhexidine gluconate mouth rinse was prescribed, and the patient was instructed to rinse gently twice daily. The patient was followed up with dental visits twice a month to screen her dental status. In this follow-up period, no dental emergency was observed that would merit emergent dental intervention.

After obtaining medical approval for dental surgical procedures, teeth extractions were performed one month after the initial assessments. The severely affected sites-the lower right first and second molars, lower left second molar, upper right first premolar, second premolar, first molar and second molar, and upper left first and second molars-were extracted. Periodontal surgical treatment (periodontal flap procedures) was performed to reduce and to eliminate any existing periodontal pockets and to create an acceptable gingival form. Periodontal dressing was applied over the surgical area to protect the region. Antibiotic therapy with amoxicillin/ clavulanic acid $1000 \mathrm{mg}$ BID was given after periodontal surgical interventions. The periodontal dressing and sutures were removed seven days after periodontal surgery. Then, the removal prosthesis was constructed three months after completion of the periodontal procedures. The periodontal and systemic health statuses of the patient were stable during the first year of her follow-up.

\section{DISCUSSION}

Several systemic disorders-such as endocrine disorders (primarily diabetes), hematological, immunological, and mucocutaneous disorders, and so on-are known to be related to various oral and dental changes. ${ }^{11}$ Periodontium is one of the most common structures or regions that these disorders may also target. Color changes, spontaneous bleeding, increased periodontal destruction, gingival overgrowth and ulcerations are the lead- 
ing periodontal findings, which may be observed in a patient with systemic disorder. ${ }^{12}$ Furthermore, acute or chronic nutritional deficiencies have been reported to be related to some periodontal disturbances. ${ }^{13}$ Several animal and human studies have documented different vitamins related to oral and periodontal disturbances. ${ }^{13}$ For example, the historical disease scurvy causes a vitamin C deficiency that results in gingivitis with hyperpla- sia, gingival bleeding and enamel hypoplasia. Vitamin $D$ deficiency has been reported to result in osteoporosis in the alveolar bone. ${ }^{11,13}$ In addition, it is not surprising to observe either glossitis or gingivitis with deficiencies of the vitamin B complex. ${ }^{14}$ Significant ulcerative lesions and gingivitis and glossitis are the typical findings with folic acid deficiency. With replacement therapy, these findings are expected to be reversible. ${ }^{15}$

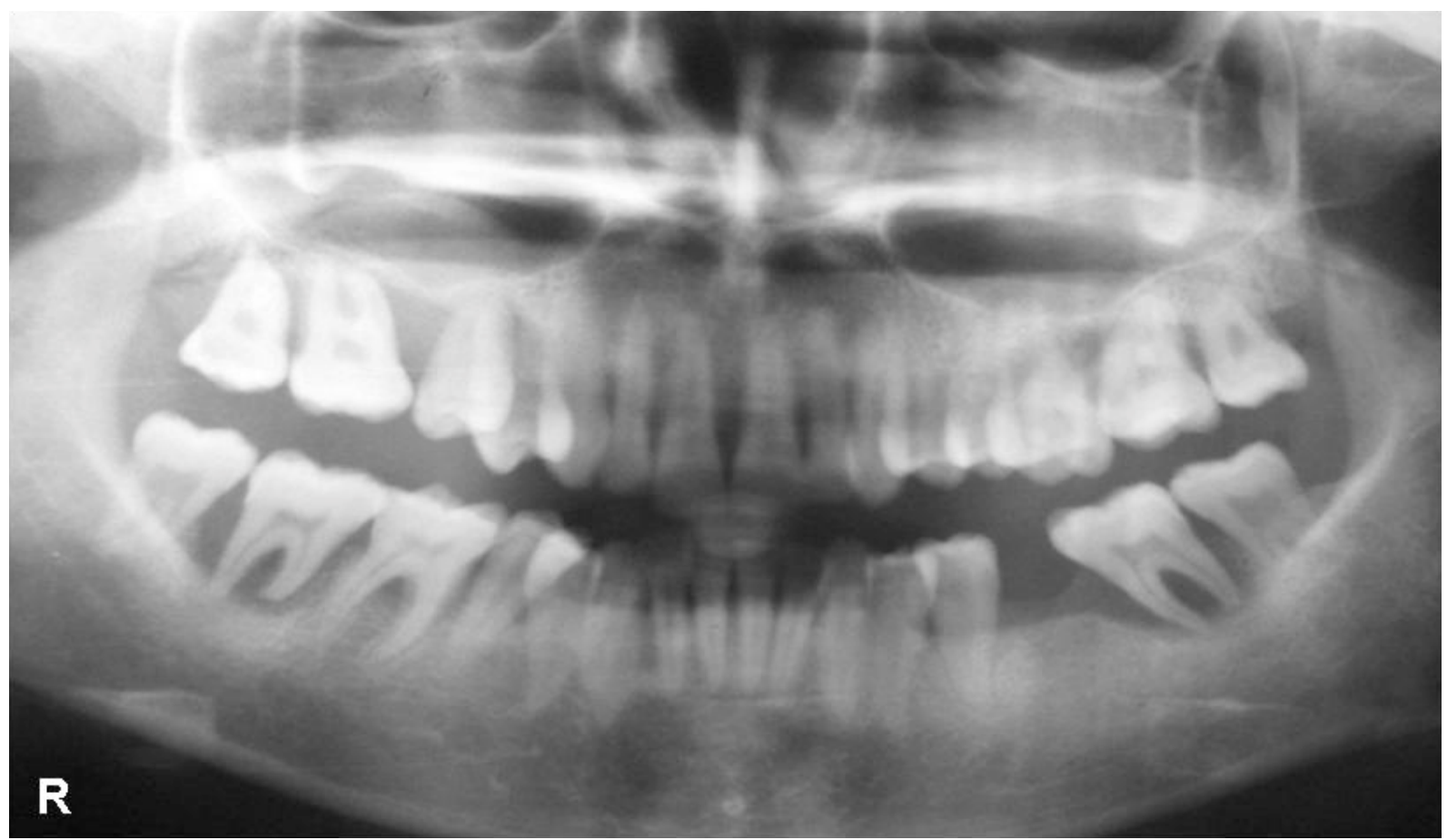

Figure 1. Patient's panoramic radiograph view.

Table 1. Blood values (Baseline, 3. and 6. months).

\begin{tabular}{|c|c|c|c|c|}
\hline Test Value & Baseline & 3th Month & 6th Month & Reference values \\
\hline WBC & 5.30 & 6.80 & 5.60 & $4.5-11 \times 10^{\wedge} 3 / \mu \mathrm{l}$ \\
\hline RBC & 2.94 & 4.42 & 4.05 & $3.8-5.1 \times 10^{\wedge} 6 / \mu \mathrm{l}$ \\
\hline HB & 4.40 & 9.20 & 12.40 & $11.7-15.5 \mathrm{~g} / \mathrm{dL}$ \\
\hline HTC (\%) & 15.70 & 30.90 & 35.40 & $35-45 \%$ \\
\hline MCV & 53.30 & 69.90 & 87.40 & $81-100 \mathrm{fL}$ \\
\hline $\mathrm{MCH}$ & 14.90 & 20.90 & 30.60 & 27-34 pg/erythrocyte \\
\hline $\mathrm{MCHC}$ & 28.00 & 29.90 & 35.00 & $32-36 \mathrm{~g} / \mathrm{dL}$ erythrocyte \\
\hline RDW & 20.90 & 36.80 & 14.70 & $11.6-14.8 \%$ \\
\hline Neutrophils & 3.40 & 4.40 & 3.30 & $1.8-7.7 \times 10^{\wedge} 3 / \mu \mathrm{l}$ \\
\hline Lymphocytes & 1.40 & 1.30 & 1.60 & $1.5-4 \times 10^{\wedge} 3 / \mu \mathrm{l}$ \\
\hline Monocytes & 0.40 & 0.60 & 0.50 & $0.2-0.95 \times 10^{\wedge} 3 / \mu \mathrm{l}$ \\
\hline Eosinophils & 0 & 0.40 & 0.10 & $0-0.7 \times 10^{\wedge} 3 / \mu \mathrm{l}$ \\
\hline Basophils & 0 & 0.10 & 0 & $0-0.15 \times 10^{\wedge} 3 / \mu \mathrm{l}$ \\
\hline Iron $\left(\mathrm{Fe}^{+2}\right)$ & 1,90 & 22.70 & 26.00 & $8.9-30.4 \mu \mathrm{mol} / \mathrm{L}$ \\
\hline TIBC & 97.10 & 83.60 & 48.80 & $44.8-80.6 \mu \mathrm{mol} / \mathrm{L}$ \\
\hline Ferritin & 1.24 & - & 23.40 & $13-150 \mathrm{ng} / \mathrm{ml}$ \\
\hline Vitamin $B_{12}$ & 130 & - & 452 & $195-870 \mathrm{pg} / \mathrm{ml}$ \\
\hline
\end{tabular}

WBC: white blood cells; RBC: red blood cells; HB: haemoglobin; HTC: hematocrit; MCV: mean corpuscular volume; MCHC: mean corpuscular hemoglobin concentration; $\mathrm{MCH}$ : mean corpuscular hemoglobin; RDW: red cell distribution width; TIBC: total iron binding capacity 
Vitamin $B_{12}$ is one of the most common nutrients, the lack of which not only causes oral lesions, but also significant systemic disturbances. ${ }^{16-17}$ Some of these may be irreversible if not properly treated. Atrophic glossitis with paresthesia, burning or purities sensation in buccal mucosa, taste alterations, denture intolerance, recurrent ulcers and cheilitis are the common oral manifestations of vitamin $B_{12}$ deficiency. ${ }^{17-18}$ However, these findings are not exclusive to vitamin $B_{12}$. All these symptoms are also common in anemia of iron deficiency related to oral manifestations. ${ }^{15}$

Vitamin $B_{12}$ deficiency may be a result of insufficient intake of this vitamin or some gastrointestinal conditions. People with gastrointestinal diseases, vegetarians, autoimmune disorders llike Graves diseases), thyroiditis and vitiligo and intake of some drugs (such as proton inhibitors) have an increased risk for Vitamin $B_{12}$ deficiency. ${ }^{15,19}$ In addition, some medications can lead to vitamin $\mathrm{B}_{12}$ deficiency, such as neomycin and colchicines. ${ }^{20}$ In an early study, the oral manifestation of vitamin $B$ complex and niacin deficiency in experimental animals include inflammation with destruction of the gingiva, periodontal ligament and alveolar bone. ${ }^{21}$ In patients with vitamin $B_{12}$ deficiency some complaints are common such as glossodynia, atrophic tongue, dysphasia, and taste aberrations. Interestingly, oral mucosa becomes a thin structure. ${ }^{20} \mathrm{~A}$ few studies demonstrate the importance of a sufficient vitamin $B_{12}$ status to maintain an adequate immune response. Vitamin $B_{12}$ involves carbon-I metabolism; thus, vitamin $B_{12}$ deficiency may result from the formation of inactive folate forms such as 5-methyl tetrahydrofolate (THF). This secondary folate deficiency subsequently contributes to DNA and RNA synthesis, which may alter immunoglobulin. ${ }^{22}$ In addition, significantly reduced numbers of lymphocytes and CD8+ and the proportion of CD4+ cells have been reported in patients with vitamin $B_{12}$ deficiency. ${ }^{22,23}$ An abnormally high CD4+/CD8+ ratio and suppressed natural killer cell activity also contribute to vitamin $\mathrm{B}_{12}$-related cellular immunological alterations. There is consistent data that demonstrate the reversal of oral manifestations with adequate treatment of vitamin $\mathrm{B}_{12}$ deficiency. ${ }^{22,23}$

Adequate delivery of oxygen to all tissues, including oral mucosa, periodontium and the teeth, is essential for the maintenance of body health.
Several factors may complicate tissue oxygenation, and anemia is the most common type of clinically significant inadequacy for impaired oxygenation. ${ }^{15,24}$ Anemia of chronic disease (ACD) and iron deficiency anemia (IDA) are among the leading causes of anemia. These types of anemia are important for dentistry not only because some oral findings may observed together with several systemic manifestations of the primary disease leading to anemia, but also because they may be recognized primarily by dental examination before more pronounced systemic manifestations of anemia are observed clinically. Several clinical and experimental studies have documented the mechanisms that cause oral alterations in patients with ACD or IDA. ${ }^{24,25}$ Furthermore, some important data are currently available and reveal that additional deficiencies of several nutrients-including trace elements and vitamins such as folic acid or vitamin $\mathrm{B}_{12}$-may further complicate oral disturbances. ${ }^{22}$

Iron is one of the most significant elements in growth and differentiation of all living cells. ${ }^{24,26}$ It is in the center of oxygen transport (hemoglobulin and myoglobulin), electron transport during mitochondrial respiration la part of complex I and Il enzymes), regulation of transcription (a central component to ribonucleotide reductase), and modulation of binding affinities of central transcription factors (with catalyzing radical processes). ${ }^{24}$ In addition, because iron is involved in the formation of free oxygen radicals with catalytic action on the metal, iron has important role on the factors in critical transcriptional activity. ${ }^{24}$ Hypoxia, induced factor-I, nuclear factor-kappa B and stress-inducible genes are the best-known domains of all these activities. These are important actors in several inflammatory processes. ${ }^{24}$ Iron plays several important roles in immunosurveillance, such as growth, promoting and differentiation-inducing functions for immune cells. In addition, it also participates in the activities of cell-mediated immune effectors pathways and cytokines. On the other hand, previous studies indicated that several cytokines, acute-phase proteins and radicals have regulatory effects on iron-homeostasis. ${ }^{24}$ Some of the important factors that, with different cellular and molecular mechanisms, may affect iron metabolism under several inflammatory conditions in humans are: TNF-Alfa, IL-1, IL-6, IFN-gamma/LPS, IL-4, IL-10, IL-13, N0, oxygen radicals, hepcidin and 
alfa1-AT. ${ }^{24}$ Some data suggest these elements of the human metabolisms may lead to hypoferremia and development of ACD. ${ }^{24}$ Differentiation of ACD from iron deficiency is essential, as iron therapy may be harmful in the absence of iron deficiency. ${ }^{24}$ The diagnosis of iron deficiency is possible with reduced serum iron, transferrin saturation and ferritin in a patient with anemia. ${ }^{20}$

\section{CONCLUSION}

In the partial list of possible diagnoses for destructive types of periodontal diseases (1999-Classification) it can be easily seen that some hematological diseases-including acquired neutropenia, leukemia and others-may affect the periodontium. ${ }^{27}$ The expression "other" is an open term for periodontal and hematological relations, a subject that requires additional research.

In the present case, it is difficult to make a decision on the relative effects of iron and vitamin $B_{12}$ deficiency on the patient's periodontal destruction. More comprehensive studies are needed on the effect of iron deficiency anemia with/without vitamin $\mathrm{B}_{12}$ deficiency on periodontium.

\section{REFERENCES}

1. Page RC: The pathology of periodontal diseases may affect systemic diseases: inversion of a paradigm. Ann Periodontol 1998;3:108-120.

2. Lainson PA., Brady PP, Fraleigh CM. Anemia A systemic Cause of Periodontal disease? J Periodontol 1968;9:35-38.

3. Erdemir EO, Nalcaci R, Caglayan O. Evaluation of systemic markers related to anemia of chronic disease in the peripheral blood of smokers and non-smokers with chronic periodontitis. Eur J Dent 2008;2:102-109.

4. Goldstein H. Systemic and Blood-Pictures Findings in Several Hundred Periclasia-Free and Periclasia-Involved Individuals. J Dent Res 1937;16:320.

5. Gokhale SR, Sumanth S, Padhye AM. Evaluation of blood parameters in patients with chronic periodontitis for signs of anemia. J Periodontol 2010;81:1202-1206.

6. Pradeep AR, Sharma A, Arjun Raju P. Anemia of Chronic Disease and Chronic Periodontitis: Does Periodontal Therapy Have Effect on Anemic Status. J Periodontol 2011;82:388-394.

7. Agarwal N, Kumar VS, Gujjari SA. Effect of periodontal therapy on hemoglobin and erythrocyte levels in chronic generalized periodontitis patients: An interventional study. J Indian Soc Periodontol 2009;13:6-11.
8. Lu S-Yu, Eng HL. Dramatic recovery from severe anemia by resolution of severe periodontitis. J Dent Sci 2010;5:41-46.

9. Hutter JW, Van der Velden U, Varoufaki A, Huffels RAM, Hek FJ, Loos BG. Lower numbers of erythrocytes and lower levels of hemoglobin in periodontitis patients compared to control subjects. J Clin Periodontol 2001;28:930-936.

10. Salvi GE, Lawrence HP, Offenbacher S, Beck JD. Influence of risk factors on the pathogenesis of periodontitis. Periodontol 2000 1997; 14:173-201.

11. Seymour RA, Heasman PA. Drugs, diseases, and the periodontium. Oxford: Oxford University Press, 1992:19-147.

12. Davies RM. Periodontal Manifestations of systemic disease. In: H.J. Jones and D.K. Mason, Eds, Oral manifestations of systemic disease. London: W. B. Saunders, 1980:514-529.

13. Katz J. Dental Correlation Nutritional Disorders. In: Kaye, D. \& Rose, L.F., Internal Medicine for Dentistry, 2. ed, eds. St Louis: Mosby Company, 1990:978-985.

14. Carranza, F.A., Influence of systemic diseases on the periodontium. In: Carranza, FA, Newmann MG. Eds. Clinical Periodontology. 8th Ed, Philadelphia: WB Saunders, 1996:185-205.

15. Ferguson MM, Dagg JH. Nutritional Disorders. In: H.J. Jones and D.K. Mason, Eds, Oral manifestations of systemic disease. London: W. B. Saunders, 1980:211-228.

16. Wray D. and Dagg JH. Diseases of the blood and bloodforming organs. In: H.J. Jones and D.K. Mason, Eds, Oral manifestations of systemic disease, London: W. B. Saunders, 1980:262-296.

17. Pétavy-Catala C, Fontès V, Gironet N, Hüttenberger B, Lorette $G$, Vaillant L. Clinical manifestations of the mouth revealing Vitamin B12 deficiency before the onset of anemia. Ann Dermatol Venereol 2003;130:191-194.

18. Cohen SG, Glick M. Dental Correlation, Anemia and Deficiency States. In: KayeD. \& Rose LF, eds. Internal Medicine for Dentistry, 2. Ed, St Louis: Mosby Company, 1990:360361.

19. Hvas AM, Nexo E. Diagnosis and treatment of vitamin B12 deficiency-an update. Haematologica 2006;91:1506-1512.

20. DeRossi SS, Raghavendra S. Anemia. Oral Surg Oral Med Oral Pathol Oral Radiol Endod 2003;95:131-141.

21. Becks H., Wainwraight WW, Morgan AF. Comparative study of oral changes in dogs due to deficiencies of pantothenic acid, nicotinic acid and unknowns of $\mathrm{B}$ vitamin complex. $\mathrm{Am}$ J Orthod Oral Surg 1943;29:183-207.

22. Maggini S, Wintergerst ES, Beveridge S, Hornig DH. Selected vitamins and trace elements support immune function by strengthening epithelial barriers and cellular and humoral immune responses. Br J Nutr 2007;98 Suppl 1:S2935 . 
23. Tamura J, Kubota K, Murakami H, Sawamura M, Matsushima T, Tamura T, Saitoh T, Kurabayshi H, Naruse T. Immunomodulation by vitamin B12: augmentation of CD8+ T lymphocytes and natural killer (NK) cell activity in vitamin B12-deficient patients by methyl-B12 treatment. Clin Exp Immunol 1999;116:28-32.

24. Weiss G. Modification of iron regulation by the inflammatory response. Best Pract Res Clin Haematol 2005;18:183-201.

25. Barry W.E. Iron Deficiency Anemia and Anemia of Chronic Disease In: KayeD. \& Rose LF, eds. Internal Medicine for Dentistry, 2. Ed, St Louis: Mosby Company, 1990:285-287.

26. Ward RJ, Crichton RR, Taylor DL, Corte LD, Srai SK, Dexter DT. Iron and the immune system. J Neural Transm 2011:118:315-328.

27. Armitage GC. Development of a Classification System for Periodontal Diseases and Conditions. Ann Periodontol $1999 ; 4: 1-6$. 